\title{
Review
}

\section{A proposed approach to monitor private-sector policies and practices related to food environments, obesity and non-communicable disease prevention}

\author{
G. Sacks"\#, B. Swinburn",2\#, V. Kraak#, S. Downs" ${ }^{3 \#}$, C. Walker ${ }^{4 \#}$, S. Barquera ${ }^{5}$, S. Friel ${ }^{6}$, C. Hawkes ${ }^{7}$, \\ B. Kelly ${ }^{8}$, S. Kumanyika ${ }^{9}$, M. L'Abbé10, A. Lee ${ }^{11,12}$, T. Lobstein ${ }^{13,14}$, J. Ma ${ }^{15}$, J. Macmullan ${ }^{16}$, S. Mohan ${ }^{17}$, \\ C. Monteiro ${ }^{18}$, B. Neal ${ }^{19}$, M. Rayner ${ }^{20}$, D. Sanders ${ }^{21}$, W. Snowdon ${ }^{1,22}$ and S. Vandevijvere ${ }^{2}$ for INFORMAS^
}

\begin{abstract}
${ }^{1}$ WHO Collaborating Centre for Obesity Prevention, Deakin University, Melbourne, Victoria, Australia; ${ }^{2}$ School of Population Health, University of Auckland, Auckland, New Zealand; ${ }^{3}$ Menzies Centre for Health Policy, University of Sydney, Sydney, New South Wales, Australia; ${ }^{4}$ Global Alliance for Improved Nutrition (GAIN), Geneva, Switzerland; ${ }^{5}$ National Institute for Public Health, Mexico City, Mexico; ${ }^{6}$ National Centre for Epidemiology and Public Health, Australian National University, Canberra, Australian Capital Territory, Australia; ${ }^{7}$ World Cancer Research Fund International, London, United Kingdom; ${ }^{8}$ School of Health and Society, University of Wollongong, Wollongong, New South Wales, Australia; ${ }^{9}$ Perelman School of Medicine, University of Pennsylvania, Philadelphia, Pennsylvania, United States of America; ${ }^{10}$ Department of Nutritional Sciences, University of Toronto, Toronto, Canada; ${ }^{11}$ School of Public Health and Social Work, Queensland University of Technology, Brisbane, Queensland, Australia; ${ }^{12}$ School of Exercise and Nutrition Sciences, Queensland University of Technology, Brisbane, Queensland, Australia; ${ }^{13}$ International Association for the Study of Obesity, London, United Kingdom; ${ }^{14}$ Public Health Advocacy Institute of Western Australia, Curtin University, Perth, Western Australia, Australia; ${ }^{15}$ Chinese Center for Disease Control and Prevention (CCDC), Beijing, China; ${ }^{16}$ Consumers International, London, United Kingdom; ${ }^{17}$ Public Health Foundation of India (PHFI), New Delhi, India; ${ }^{18}$ School of Public Health, University of São Paulo, São Paulo, Brazil; ${ }^{19}$ The George Institute for Global Health, University of Sydney, Sydney, New South Wales, Australia; ${ }^{20}$ British Heart Foundation Health Promotion Research Group, University of Oxford, Oxford, United Kingdom; ${ }^{21}$ School of Public Health, University of the Western Cape, Cape Town, South Africa; ${ }^{22}$ Pacific Research Centre for the Prevention of Obesity and Non-communicable Diseases (C-POND), Suva, Fiji
\end{abstract}

\begin{abstract}
Summary
Private-sector organizations play a critical role in shaping the food environments of individuals and populations. However, there is currently very limited independent monitoring of private-sector actions related to food environments. This paper reviews previous efforts to monitor the private sector in this area, and outlines a proposed approach to monitor private-sector policies and practices related to food environments, and their influence on obesity and non-communicable disease (NCD) prevention. A step-wise approach to data collection is recommended, in which the first ('minimal') step is the collation of publicly available food and nutrition-related policies of selected private-sector organizations. The second ('expanded') step assesses the nutritional composition of each organization's products, their promotions to children, their labelling practices, and the accessibility, availability and affordability of their products. The third ('optimal') step includes data on other commercial activities that may influence food environments, such as political lobbying and corporate philanthropy. The proposed approach will be further developed and piloted in countries of varying size and income levels. There is potential for this approach to enable national and international benchmarking of private-sector policies and practices, and to inform efforts to hold the private sector to account for their role in obesity and NCD prevention.
\end{abstract}

Keywords: INFORMAS, non-communicable diseases, obesity prevention, private sector.

obesity reviews (2013) 14 (Suppl. 1), 38-48

Address for correspondence: G Sacks, WHO Collaborating Centre for Obesity Prevention, Deakin University, 221 Burwood Highway, Burwood, Vic. 3125, Australia.

E-mail: gary.sacks@deakin.edu.au

"Members of the writing group for this manuscript, listed in order of their contribution to the writing of the manuscript. NINFORMAS is the International Network for Food and Obesity/non-communicable diseases Research, Monitoring and Action Support. All authors who are not members of the writing group are listed in alphabetical order, and contributed to discussion of the key concepts and issues raised in this manuscript as part of the first formal meeting of INFORMAS from 19 to 23 November 2012. 
'Efforts to prevent non-communicable diseases go against the business interests of powerful economic operators. In my view, this is one of the biggest challenges facing health promotion.'

Margaret Chan, Director-General of the World Health Organization, June 2013 (1)

\section{Background}

Private-sector organizations, including all industry stakeholders involved in producing, packaging, distributing and marketing foods and beverages (collectively referred to as 'the food industry'), as well as entertainment companies and the media, are critical in shaping the food environments of individuals and populations worldwide (2). Through integrated marketing communications, privatesector organizations also influence people's attitudes, perceptions, and desires, as well as social norms and values (3). The food industry, in particular, has been criticized for its part in making food environments unhealthier over recent decades (4-8), and transnational food companies have been identified as major drivers of non-communicable disease (NCD) epidemics (8). Moreover, the food industry has been accused of undermining public health efforts, through their power and influence over political processes $(1,8)$. However, it is also widely acknowledged that the private sector has the collective power to be a major contributor to making food environments healthier $(2,9,10)$. Indeed, the World Health Organization (WHO) and the United Nations (UN) recognize that there is a role for the private sector in efforts to reduce NCDs, and their key publications in this area identify specific roles for the private sector with respect to food environments (see Table 1). The WHO and UN recommendations for the private sector were echoed in the 2011 Lancet Obesity Series (10), which also called for the private sector to use all available strategies to support public health efforts to create healthier food systems, and to support efforts to monitor progress towards healthier food systems by the sharing of relevant data.

In response to these calls to action, individual companies (particularly in the food industry) and industry representative bodies have acknowledged the important role they can play to support healthy food environments. Many privatesector organizations have announced policies to improve food composition, provide clear nutrition labelling and reduce marketing of unhealthy foods to children (11-14). Some companies have delivered on their public commitments and are on track to achieve further improvements; while others have either not made meaningful commitments or have failed to achieve expected progress, such as in the area of food marketing (14-16).

For the most part, private-sector pledges have been governed by industry self-regulation and voluntary codes of
Table 1 Recommended actions for the private sector with respect to food environments in the Global Strategy for Diet and Physical Activity and the United Nations Political Declaration on Non-communicable Diseases
Recommended actions for the private sector in the 2004 World Health Organization (WHO) Global Strategy for Diet and Physical Activity (DPAS) (2):

- Limit the levels of saturated fats, trans-fatty acids, free sugars and salt in existing products, and consider introducing new products with better nutritional value;

- Continue to develop and provide affordable, healthy and nutritious choices to consumers;

- Practise responsible marketing that supports DPAS, particularly with regard to the promotion and marketing of foods high in saturated fats, trans-fatty acids free sugars or salt, especially to children;

- Provide consumers with adequate and understandable product and nutrition information;

- Issue simple, clear and consistent food labels, and evidence-based health claims that will help consumers to make informed and healthy choices with respect to the nutritional value of food;

- Promote healthy diets and physical activity in accordance with national guidelines, international standards and the overall aims of DPAS; and

- Provide information on food composition to national authorities.
Recommended actions for the private sector in the 2011 United Nations (UN) Political Declaration on Non-communicable Diseases (9):

- Take measures to implement the WHO set of recommendations to reduce the impact of the marketing of unhealthy foods and non-alcoholic beverages to children, while taking into account existing national legislation and policies;

- Consider producing and promoting more food products consistent with a healthy diet, including by reformulating products to provide healthier options that are affordable and accessible and that follow relevant nutrition facts and labelling standards, including information on sugars, salt and fats, and where appropriate, trans-fat content;

- Promote and create an enabling environment for healthy behaviours among workers;

- Work towards reducing the use of salt in the food industry in order to lower sodium consumption. practice agreed either between government and the private sector or initiated exclusively by industry, often as part of social responsibility initiatives $(17,18)$. These voluntary approaches have delivered some progress in a small number of areas, such as reducing dietary salt in some countries $(19,20)$ and restricting a small amount of advertising $(12,15)$, but outcomes are typically weak and uncertain in the absence of independent monitoring, evaluation and compliance programmes, particularly for changing marketing practices that influence the food purchases and diets of children and adolescents $(11,17,21,22)$.

The WHO, through its Member States, currently conducts an NCD monitoring programme, with a predominant focus on health outcomes (NCD mortality and morbidity), health risk factors and health system responses (23). However, as part of global efforts to monitor progress in creating healthy food environments, there is also a need to 
monitor more 'upstream' factors that affect the accessibility, availability, affordability and acceptability of food (24), including the impact of the private sector (25-28). The systematic monitoring of private-sector policies and practices has the potential to enable benchmarking of organizations at the national and international levels. It can also assist efforts to hold the private sector to account for their role in obesity and NCD prevention, and help organizations to improve their nutrition-related policies and practices.

The International Network for Food and Obesity/NCD Research, Monitoring and Action Support (INFORMAS) is a global network of public-interest organizations and researchers that aims to monitor, benchmark, and support public- and private-sector actions to create healthy food environments and reduce obesity, NCDs and their related inequalities (29). A key module of INFORMAS is the monitoring of private-sector policies and practices that influence food environments. This paper's aim was to review previous efforts to monitor the private sector in this area, and outline a proposed approach to monitor private-sector policies and practices as part of INFORMAS. The intention is that the approach outlined in this paper will be further developed and pilot tested in countries of varying size and income levels. The proposed monitoring approach is designed to answer the research question, 'How are private-sector organizations affecting food environments and influencing obesity/NCD prevention efforts?'

In line with the scope of INFORMAS (29), this paper focuses on private-sector policies and practices regarding food environments related to obesity and NCDs. It does not include policies and practices related to tobacco control, physical activity, undernutrition, micronutrient deficiencies, breastfeeding or alcohol.

\section{Review of previous efforts to monitor private-sector policies and practices related to food environments}

A literature search was conducted to identify previous efforts to monitor private-sector policies and practices related to food environments from an obesity and NCD prevention perspective. As a starting point, a search of the Google Scholar database was conducted to identify relevant research papers and reports. From the references cited in the papers and reports found, additional relevant papers, reports, websites and surveys were identified (snowball sampling). Supplementary materials were identified based on the authors' expertise and knowledge in the area.

The results of the search indicated that there is currently limited independent monitoring of private-sector performance in relation to public health nutrition. This is in contrast to the detailed auditing of the private sector with respect to their financial, environmental and social welfare performance (30). It is only in the last decade that increased attention has been paid to the role of the food industry, and entertainment and media organizations in the prevention of obesity and NCDs.

The first major assessments of food industry performance in this area came from the investment banking sector in the early 2000s, where the extent to which the largest food manufacturing companies were exposed to health-related market, regulatory and litigation risks were assessed (31,32). Using companies' public disclosure of their activities in annual reports and corporate websites, these studies identified substantial reputational and financial exposure of companies to the high burden of NCDs and the obesity epidemic in the United States. The investment banks repeated these studies more recently with comparable findings, also noting the projected costs associated with obesity, and the potential business opportunities for companies to pursue activities to support healthy lifestyles and healthier product portfolios $(33,34)$.

Publicly available corporate reports and websites were also used in a broader study to monitor private-sector activities influencing food environments in 2006 (11). The study examined the commitments and pledges of 25 of the largest food companies worldwide (including food and non-alcoholic beverage manufacturers, food retailers and food service providers) in response to the concerns raised by the Global Strategy on Diet and Physical Activity (DPAS) (2) and found that, with some notable exceptions, the world's food companies were not fully engaged with the seriousness and urgency of the DPAS recommendations (11).

An increasing number of research studies and monitoring initiatives focused on the marketing practices of the largest food and beverage manufacturers have been conducted recently $(12,14,15,35,36)$. In addition, ongoing initiatives to monitor private-sector pledges to reduce marketing of unhealthy foods to children and adolescents are being conducted in the United States and internationally (37-39). Independent studies have consistently found that, while some companies are performing well and taking positive steps to address the WHO recommendations, the existing self-regulatory frameworks have not resulted in significant progress to improve diets and public health outcomes $(35,40,41)$.

Several independent research studies and monitoring initiatives focused on food service providers, and quickservice restaurants (QSRs) in particular, have also been conducted recently (42-46). Some of these studies show the high volume of marketing undertaken by these organizations, point out the limitations of the existing selfregulatory approaches in place to limit marketing to children and adolescents, and highlight the need for QSRs to do more collectively to develop and promote more 
nutritious menu items that are lower in total energy content, fat, saturated fat and salt.

In the United Kingdom (UK), there has also been research into the performance of food retailers with respect to their public health efforts (47-49). These studies examined the major food retailers (supermarket chains) with respect to the nutritional content of their 'own-brand' foods, labelling information, in-store promotions and product positioning, customer information and advice, and checkout offerings, and showed varying performances by each organization with indications of positive changes over time.

There has been very limited monitoring of other privatesector practices that influence food environments, such as public-private partnerships (PPPs) and social responsibility practices focused on addressing hunger, food insecurity, nutrition, and consumer health (50,51). Governments, non-government organizations (NGOs) and private-sector organizations are increasingly using PPPs and other multisectoral collaborations, coalitions and strategic alliances to respond to rising rates of overweight, obesity and lifestylerelated chronic diseases in many countries worldwide. Examples include the European Platform for Action on Diet, Physical Activity and Health (2005 to 2010) (27); the Healthy Weight Commitment Foundation in the United States (initiated in 2009) (13); and the Public Health Responsibility (PHR) Deal Networks in England (initiated in 2011) (52). However, the public health outcomes of these arrangements are unclear (53). Importantly, a UK parliamentary report into the PHR Deal Networks conveyed serious doubts about the effectiveness of pledges made under this PPP (54).

The Access to Nutrition Index (ATNI) (55), funded and developed through a partnership between the Global Alliance for Improved Nutrition, The Bill and Melinda Gates Foundation and the Wellcome Trust, is a monitoring initiative that evaluates food and beverage manufacturers on their nutrition-related commitments, disclosure practices, and performance related to obesity and undernutrition. ATNI uses a broad set of indicators across multiple categories, including corporate governance, product portfolio, accessibility of products, marketing practices, support for healthy lifestyles, food labelling and health claims, and stakeholder engagement, to score individual companies on a scale of zero to ten reflecting adherence to promising or best practices. A combination of publicly available data, data sourced through direct interviews with company representatives, and customized market-research data are used to score each company against each indicator. Scores are then weighted and combined across categories to produce an overall ranking for each company. This initiative offers the most comprehensive monitoring of the nutrition-related activities of food and beverage manufacturers to date. The initial assessment of the largest 25 food and beverage manufacturers globally, released in 2013, found that most companies rated poorly (scored less than 5 out of 10) and that there is substantial scope for companies to improve food environments (55). The assessment found that company practices often do not measure up to their nutrition commitments and policies, and that there is a lack of transparency about companies' nutrition practices (55).

\section{Proposed monitoring approach}

The proposed step-wise data collection approach for monitoring private-sector policies and practices related to food environments, obesity and NCD prevention is outlined in Fig. 1. This approach has been developed in accordance with the key principles of INFORMAS, as outlined by Swinburn et al. in this supplement (29). It is proposed that monitoring activities are conducted in each participating country, with relevant public-interest stakeholder groups in each country selecting an appropriate set of monitoring activities based on the resources available, and tailored to the local context. It is recommended that data collection activities occur regularly (e.g. every two years, or when significant changes in the corporate or regulatory environment occur) in each country to enable assessment of trends and updates to benchmarks of good practice.

\section{Prioritizing the organizations to monitor}

While food-related private-sector organizations are often referred to collectively as 'the food industry', there are a diverse range of private-sector stakeholder groups within the food system. Key private-sector stakeholder groups whose activities most directly shape food environments include agribusiness; food and beverage manufacturers; food retailers, including supermarkets; food service providers, including QSRs; industry trade associations and peak bodies; and entertainment and media organizations (56). Other private-sector stakeholder groups, e.g. food wholesalers, food distributors (including importers and exporters), and the advertising and marketing industry (57), are also influential in many contexts. Among the different stakeholder groups in different countries, there is typically a range of large trans-national companies, national companies, and small and medium enterprises.

Under the proposed monitoring approach, it is recommended that monitoring activities are prioritized to focus on the sectors within the food industry that pose the greatest threat and/or have the greatest opportunity to improve public health nutrition. In order to prioritize the privatesector organizations to monitor in a particular country ('organizations of interest'), it is recommended that each country first conducts a high-level contextual analysis of the private-sector organizations that influence the national food system. This can involve consultation with experts 


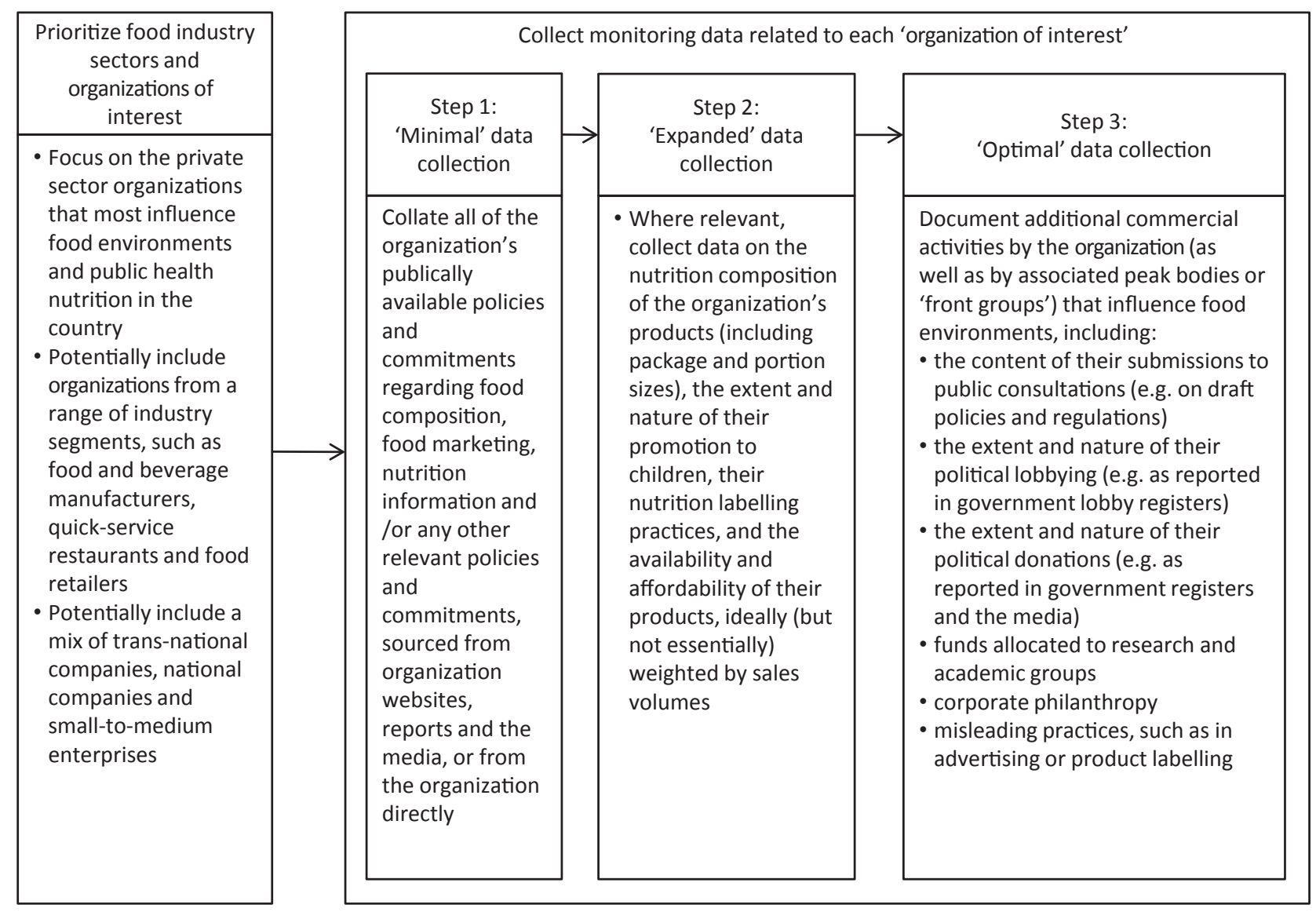

Figure 1 Proposed step-wise data collection approach for monitoring private-sector policies and practices that affect food environments and influence obesity/non-communicable disease prevention efforts.

with local knowledge of the food system, as well as analysis of sales volume or market share data by industry type, where it is available (e.g. through government macroeconomic data, and databases such as EuroMonitor). Based on this analysis, each country should consider including approximately $15-25$ 'organizations of interest', taking into account the size of the organization, the products and services they provide, and their level of influence. In most countries, the focus is likely to be on large food and nonalcoholic beverage manufacturers, major food retailers, and QSR chains, although the prioritization of organizations to monitor is likely to be context-specific to some degree. In many cases, it may also be important to include industry associations and peak bodies in the analysis. Where relevant, organizations that are known to have demonstrated particularly good or harmful practices should be included as case studies. It is envisaged that more detailed guidelines and protocols for selecting organizations of interest will be developed in time, informed by pilot testing of the proposed approach in countries of varying size and income levels.

\section{Step-wise approach to data collection}

Once the organizations of interest have been selected, a step-wise ('minimal', 'expanded' and 'optimal') approach to data collection is proposed (refer to Fig. 1), with the level of data collection selected based on the resources available.

In formulating the priorities for data collection under the proposed approach, a distinction is made between the monitoring of 'policies' and the monitoring of 'practices' or 'actions'. The monitoring of stated organizational policies and commitments (e.g. company policies and pledges related to product composition and food reformulation, the reduction of food marketing to children, and the provision of nutrition information), particularly when they are publicly available (e.g. on company websites), requires relatively few resources and can be conducted at relatively low cost. In contrast, the monitoring of the 'practices' of organizations (e.g. the nutrition composition of a company's products, the extent and nature of their marketing to children, the prices of their products, and their lobbying activities), are typically more difficult and more expensive 
to monitor. While 'practices', rather than stated policies, have a more direct influence on food environments, the proposed monitoring approach nevertheless prioritizes the monitoring of stated policies because they are easier and cheaper to collect as a first step. In recommending this approach, it is also recognized that organizational policies, and the public disclosure of these policies, are often a starting point for generating action, and that it is reasonable to expect large food companies to have publicly available policies on key aspects of nutrition, and to be held accountable for their implementation.

\section{Step 1: 'Minimal' data collection}

The first ('minimal') step of data collection under the proposed approach, therefore, involves the collation of relevant publicly available policies and commitments of each organization of interest (refer to Fig. 1). In line with global recommendations for the private sector with respect to food environments (refer to Table 1), the most critical organizational policies to monitor are those related to food composition (primarily with respect to the reduction of salt, trans-fatty acids, saturated fat and added/free sugars), the reduction of food marketing to children, the provision of nutrition information, and the availability and affordability of their products. These policy areas are of most relevance to food and beverage manufacturers, food service providers, and food retailers. Organizations from other industry segments may have relevant policies in these and other areas, particularly related to food marketing and the well-being of their own staff members.

Sources for these data include requests to the organizations directly, company websites, corporate financial and social responsibility reports, and company media releases. Relevant policies of industry trade organizations or peak bodies are also likely to be valuable data sources.

If resources allow, publicly available data on organizational policies can be supplemented by interviews with representatives from each organization. This may provide more detailed insight into relevant policies. For food and beverage manufacturers, the ATNI methodology, which incorporates interviews with company representatives, may be an appropriate tool to assist in this aspect of data collection, and ATNI could potentially be modified for use in other industry segments.

\section{Step 2: 'Expanded' data collection}

The second ('expanded') step of data collection under the proposed monitoring approach, to be conducted for each organization of interest (where relevant), involves collection of data on the nutritional composition of the organization's products (as well as package and portion sizes), the extent and nature of their promotion to children, their nutrition labelling practices, and the availability and affordability of their products (refer to Fig. 1). These areas of action have been prioritized in line with the global recommendations for the private sector with respect to food environments (refer to Table 1).

The ATNI methodology provides potentially the most rigorous data collection tool for assessing these nutrition practices of food and beverage manufacturers (55), and is likely to be a valuable data collection tool. However, an ATNI assessment is relatively resource-intensive to conduct, and therefore may not be appropriate as a data collection methodology in many countries. Furthermore, ATNI has been designed specifically for food and beverage manufacturers, and so may not be suitable for the monitoring of organizations in other industry segments (e.g. food retailers, food service providers), although there may be scope to modify ATNI for use in these areas.

An alternative method of data collection is for countries to use relevant data collected in other modules of INFORMAS, for example, nutrition composition data (58), data on the extent and nature of food promotion to children (59), data on nutrition labelling (60) and data on food prices (61). Data from the various INFORMAS modules can be brought together and analysed by organization to understand the nutrition practices of each organization of interest.

Ideally, the data collected for each organization (e.g. nutritional composition data for the full range of an organization's products) will be combined with sales volume data (sourced from government macroeconomic data and databases such as EuroMonitor) as a way of weighting the data to enable assessment of each organization's impact on the healthiness of the food supply. The ideal data set would incorporate sales data that is broken down by socioeconomic group or geographic area within a country to enable analysis of the influence of a particular organization on the healthiness of foods sold to vulnerable groups within society. It is recognized, however, that this level of granularity of data is likely to prove expensive to procure, if it is available at all.

\section{Step 3: 'Optimal' data collection}

The third ('optimal') step of data collection under the proposed monitoring approach (refer to Fig. 1), includes the monitoring of other commercial activities that influence food policy and action. These activities (such as political lobbying; political donations, corporate philanthropy, and funds allocated to research and academic groups) have been identified as critical in influencing public health promotion efforts and/or deflecting criticism of food industry practices $(7,8,62,63)$. It is crucial to document these activities as broadly as possible as part of holding private-sector organizations to account for their role in obesity/NCD prevention.

The vast majority of these commercial activities that influence food environments are not routinely publicly 
reported, and many are, by their nature, difficult to monitor. As such, a systematic and comprehensive understanding of the political influences of the private sector and the tactics they use to promote their own interests is unlikely to be achievable at this time. However, there are several data collection avenues that may provide some insight, and warrant investigation as potential data sources:

- Some relevant activities are reported by large companies in their financial and social responsibility reports. However, nutrition and consumer health are not typically included in the international standards for social responsibility indicators $(64,65)$, and key global social responsibility reporting systems lack specific indicators for companies to assess progress towards achieving nutrition and consumer health outcomes (66). This, combined with the voluntary nature of most social responsibility reporting, means that not all relevant activities are likely to be disclosed in social responsibility reports.

- In many countries, governments have formal processes in place for public consultation on draft policy or legislative documents. In many cases, the formal submissions of private-sector organizations to these consultations are publicly available, and can be analysed to ascertain the views of organizations in particular policy areas. In addition, the position of a particular company (or the industry in general) on particular issues can be gleaned from their comments in the media, press releases, policy statements by industry groups and peak bodies, and papers in trade journals.

- With respect to political lobbying, some governments (e.g. the United States) and institutions (e.g. Corporate Europe Observatory) maintain lobbying registers that can be scrutinized to identify activities that could potentially influence food environments. However, the level of detail in these registers is typically very low, and the registers do not include 'informal' or private lobbying.

- Public-interest NGOs, such as Corporate Accountability International, Corporate Europe Observatory and the Obesity Policy Coalition in Australia, monitor a wide range of commercial activities across a number of domains, including those related to food environments (67).

- One increasingly common way that the food industry attempts to shape food policy and public discourse is by forming a group that appears to benefit the public (68). Often these groups claim to represent consumers or other public-interest groups when, in fact, they are funded by large private-sector organizations. The websites and other outputs from these 'front groups' can be monitored and the content analysed.

- Many relevant private-sector activities are examined by investigative journalists who report specific activities through the media $(69,70)$. In addition, social media, crowd-sourcing tools, and whistle-blower services offer sig- nificant potential to draw on wide-ranging data sources for monitoring the practices of the private sector. However, as it is often difficult to verify the reliability and credibility of these sources, these may not be appropriate sources to use as part of a formal monitoring programme.

\section{Measurement indicators}

It is proposed that a number of summary indicators related to each component of the monitoring approach are used to describe the influence of the private sector on food environments. Examples of potential summary indicators include:

- Percentage of the largest 10 food and beverage manufacturers in a particular country with policies related to the reduction of food marketing to children;

- Percentage change in mean salt content of products sold, by organization;

- Amounts spent on political lobbying by each of the largest private-sector organizations in the food industry.

Where sales volume data have been obtained (see 'Step 2'), nutrient composition data can be weighted by sales to enable an assessment of each organization's impact (where relevant) on the healthiness of the food supply, potentially including changes over time, across countries, and ideally, among different socioeconomic groups. This assessment would also require use of a classification scheme (nutrient profiling system) for determining the relative healthiness of a particular product or category of products. It is recommended that, where possible, a common nutrient profiling system or systems are used across INFORMAS activities (29).

In addition, it is proposed that the performance of each organization is assessed against current good practice. This information could then be used to rank organizations on their performance, either across multiple areas such as marketing, food composition, and labelling, or with respect to their performance in one area (e.g. marketing) only. Rankings may be within industry segments (e.g. food and beverage manufacturers, food retailers) or across the board, as appropriate. Where relevant, the publication and promotion of rankings of organizations may serve to encourage competition among those organizations, and this could be an important impetus for positive change.

It is noted, however, that in most areas, there are currently no relevant globally endorsed guidelines, targets or standards in place that can be used as measures of good practice. ATNI provides the most comprehensive tool to rate the nutrition practices of food and beverage manufacturers across multiple areas, and allocates each organization a score out of 10 both overall and in each content area (55). This could provide a basis for developing benchmarking criteria even where an ATNI assessment has not been 
conducted. Nevertheless, detailed assessment protocols that identify components to incorporate, processes for assessment, and weighting criteria need to be developed prior to data collection, and can be refined during pilot testing. Assessments will need to take into account the content of policies and commitments (targets for action should be measurable, meaningful and specific), the degree of transparency and disclosure of the organization (independent monitoring of practices is encouraged), and the concordance between an organization's policies and their practices, while allowing for assessment guidelines to be periodically revised in order to reflect changes in feasible best practice.

\section{Implementation considerations}

The proposed monitoring approach has been designed to facilitate the monitoring of private-sector policies and practices in a wide range of countries, allowing flexibility at the local level. The step-wise approach to data collection is intended to allow groups from all countries, even those with minimal resources, to participate.

It is expected that in some high-income countries, the largest food companies will have publicly available policies regarding some aspects of food composition, marketing to children and food labelling. However, in the vast majority of countries, and for the vast majority of private-sector organizations, it is likely that there is currently little publicly available information on these and other relevant policy components. Even in the case of trans-national companies, their policies are typically not uniform across countries and are not applied to all markets. The lack of publicly available data will severely limit the extent of analysis that can be completed for many countries, even at the 'minimal' level of data collection. Nevertheless, the presence/absence of policies is still worth recording for benchmarking and comparison purposes, as a baseline for measuring future progress, and as a means for encouraging greater disclosure. Indeed, a valuable first step for INFORMAS would be to highlight the need for greater disclosure of corporate food- and nutrition-related policies.

The types of organizations selected for monitoring in each country is likely to vary, and this is likely to create implementation issues that need to be considered. Within countries, it may be problematic to directly compare organizations with different product portfolios or in different industry segments. The ability to make meaningful comparisons of results over time is also likely to be limited because of the dynamic nature of the corporate sector in which companies frequently buy and sell brands, and product portfolios often change markedly from year to year.

The focus on only the most prominent organizations in a country is likely to draw increased media attention to those companies, which, on the one hand, could potentially disadvantage small organizations that do not receive the same level of attention, but on the other hand, may deflect criticism away from smaller competitors. The inclusion of some smaller organizations as case studies could help address these potential issues. Between countries, the selection of different types of organizations may limit comparability. However, it may be possible to compare organizations of similar sizes across countries. Ideally, groups undertaking monitoring in different countries will collaborate through INFORMAS to ensure that at least some organizations are investigated in multiple countries. This will enable analysis of their differential policies and practices in different areas, while avoiding duplication of data collection in common areas. The pilot testing of the proposed monitoring approach in countries of varying size and income levels will assist in further defining methods for selecting organizations of interest and comparison of results.

ATNI is currently the most sophisticated tool available for monitoring the nutrition-related policies and practices of private-sector organizations. ATNI incorporates aspects of each of the three steps of the proposed monitoring approach, and its widespread use could be a key mechanism for implementing the proposed approach. However, details of how ATNI can be used in multiple countries and by groups external to the ATNI organization are still to be developed. Where ATNI is conducted for a particular country, it is likely to form a major part of the data collection effort, but will need to be supplemented (where possible) by other data collection methods to include areas not covered by ATNI, e.g. data about food retailers and QSRs, and data about lobbying activities.

While monitoring of private-sector policies and practices is currently relatively underdeveloped, as more monitoring takes place and accountability mechanisms improve, it is expected that the tools, protocols and measurement indicators will advance. Private-sector organizations can facilitate their accountability by sharing relevant data (e.g. policies, commitments, nutrition information) with publicinterest groups. While it is recognized that some data (such as marketing spend and sales volumes) are likely to be commercially sensitive and proprietary, private-sector organizations are encouraged to provide as much data to national authorities and NGOs as possible, in a timely fashion (9). The release of commercially sensitive information can be avoided in a number of ways, such as by providing historic data (e.g. greater than 1 year old), by removing brand names from information provided, or by working with a trusted entity that pools the data and coordinates external monitoring activities (e.g. as per the arrangements developed by the Healthy Weight Commitment Foundation in the United States (13)).

While the focus of this paper is on monitoring the private sector, there is also an important role for governments 
in this area. Most pertinently, governments are critical in shaping the regulatory environment in which the private sector operates. Accordingly, the policies and practices of the private sector are highly dependent on the actions of governments. Furthermore, governments can play a role in requiring the private sector to disclose certain information. Monitoring the roles of government is addressed in the companion paper in this series (71).

\section{Conclusion}

This paper has outlined a proposed step-based approach to monitor private-sector policies and practices related to food environments. This approach has the potential to assess the extent to which private-sector organizations, in a range of countries, are contributing to and supporting obesity/NCDs prevention on the one hand, or undermining attempts to implement public health policy solutions on the other hand.

It is envisaged that the data collected under the proposed approach will enable national and international benchmarking and comparisons of private-sector policies and practices. This will assist in holding the private sector to account for their role in obesity and NCD prevention efforts. The data are also likely to make an important contribution to a global database for research into the determinants of obesity and NCDs, and for evaluating the impact of potential solutions.

The next steps in progressing the systematic monitoring of private-sector policies and practices are to develop detailed protocols for data collection and analysis, and to trial data collection methods in a range of different countries. While many of the methods for data collection and analysis are still developing, it is nevertheless important to collect what information is readily available, raise awareness of the importance of greater transparency, and highlight the need for independent monitoring of the private sector in this area.

\section{Acknowledgements}

The Rockefeller Foundation kindly supported the work of INFORMAS by hosting the first formal meeting of INFORMAS at the Rockefeller Foundation Bellagio Centre, Italy from 19 to 23 November 2012. The following organizations provided funding support for the travel of participants to Italy for this meeting and the preparation of background research papers: The Rockefeller Foundation, International Obesity Taskforce (IOTF), University of Auckland, Deakin University, The George Institute, University of Sydney, Queensland University of Technology, University of Oxford, University of Pennsylvania Perelman School of Medicine, World Cancer Research Fund International, University of Toronto, and The Australian
National University. The authors would like to thank Francesco Branca and Godfrey Xuereb from the World Health Organization, and Janice Albert from the Food and Agriculture Organization for their participation in the first formal meeting of INFORMAS, and for their input into this paper. The Faculty of Health at Deakin University kindly supported the costs for open access availability of this paper, and the Australian National Health and Medical Research Council Centre for Research Excellence in Obesity Policy and Food Systems (APP1041020) supported the coordination and finalizing of INFORMAS manuscripts.

\section{Conflicts of interest}

Bruce Neal is the Chair of the Australian Division of World Action on Salt and Health (2007-ongoing), was a Member of the Pepsico Global Scientific Advisory Board (20102012), was the Independent Adjudicator for the Australian Responsible Marketing to Children's Initiative (20092010) and holds funding from the Australian Food and Grocery Council as part of a National Health and Medical Research Council of Australia Partnership project (20102014). The other authors declare that they have no competing interests.

\section{References}

1. Chan M. Opening address at the 8th Global Conference on Health Promotion, Helsinki, Finland, 10 June 2013, 2013. [WWW document]. URL http://www.who.int/dg/speeches/2013/health _promotion_20130610/en/ (accessed June 2013).

2. World Health Organization. Global Strategy on Diet, Physical Activity and Health. World Health Organization: Geneva, 2004.

3. Kitchen P, Brignell J, Li T, Jones G. The emergence of IMC: a theoretical perspective. J Advert Res 2004; 44: 19-30.

4. Brownell K, Horgen K. Food Fight: The Inside Story of the Food Industry, America's Obesity Crisis and What We Can Do About It. Contemporary Books: Chicago, IL, 2004.

5. Nestle M. Food Politics: How the Food Industry Influences Nutrition and Health. University of California Press: Los Angeles, CA, 2002.

6. The PLoS Medicine Editors. PLoS medicine series on big food: the food industry is ripe for scrutiny. PLoS Med 2012; 9: e1001246.

7. Brownell KD, Warner KE. The perils of ignoring history: big tobacco played dirty and millions died. How similar is Big Food? Milbank Q 2009; 87: 259-294.

8. Moodie R, Stuckler D, Monteiro C et al. Profits and pandemics: prevention of harmful effects of tobacco, alcohol, and ultraprocessed food and drink industries. Lancet 2013; 381: 670-679. 9. United Nations. Political Declaration of the High-level Meeting of the General Assembly on the Prevention and Control of Noncommunicable Diseases. New York: United Nations, General Assembly, 2011.

10. Gortmaker SL, Swinburn BA, Levy D et al. Changing the future of obesity: science, policy, and action. Lancet 2011;378: 838-847. 
11. Lang T, Rayner G, Kaelin E. The Food Industry, Diet, Physical Activity and Health: A Review of Reported Commitments and Practice of 25 of the World's Largest Food Companies. City University: London, 2006.

12. EU Pledge. EU Pledge 2010 Monitoring Report, 2010. [WWW document]. URL http://www.eu-pledge.eu (accessed November 2012).

13. Healthy Weight Commitment Foundation. Food and beverage manufacturers pledging to reduce annual calories by 1.5 trillion by 2015, 2010. [WWW document]. URL http://www .healthyweightcommit.org (accessed November 2012).

14. Hawkes C, Harris JL. An analysis of the content of food industry pledges on marketing to children. Public Health Nutr 2011; 14: 1403-1414.

15. Center for Science in the Public Interest (CSPI). Report Card on Food-Marketing Policies: An Analysis of Food and Entertainment Company Policies Regarding Food and Beverage Marketing to Children, 2010. [WWW document]. URL http://www .cspinet.org/marketingreportcard (accessed November 2012).

16. Kraak VI, Story M, Wartella EA. Government and school progress to promote a healthful diet to American children and adolescents: a comprehensive review of the available evidence. Am J Prev Med 2012; 42: 250-262.

17. Sharma LL, Teret SP, Brownell KD. The food industry and self-regulation: standards to promote success and to avoid public health failures. Am J Public Health 2010; 100: 240-246.

18. Hawkes C, Lobstein T. Regulating the commercial promotion of food to children: a survey of actions worldwide. Int J Pediatr Obes 2011; 6: 83-94.

19. van Raaij J, Hendriksen M, Verhagen H. Potential for improvement of population diet through reformulation of commonly eaten foods. Public Health Nutr 2009; 12: 325-330.

20. Webster JL, Dunford EK, Hawkes C, Neal BC. Salt reduction initiatives around the world. J Hypertens 2011; 29: 1043-1050.

21. Hawkes C. Self-regulation of food advertising: what it can, could and cannot do to discourage unhealthy eating habits among children. Nutr Bull 2005; 30: 374-382.

22. Accenture. Compliance Monitoring Report for the International Food \& Beverage Alliance on Global Advertising on Television, Print and Internet, 2012. [WWW document]. URL https:// www.ifballiance.org/sites/default/files/IFBA \%20Accenture\%20 Monitoring\%20Report\%202011\%20FINAL\%20010312.pdf (accessed November 2012).

23. World Health Organization. Draft action plan for the prevention and control of noncommunicable diseases 2013-2020, 2013. [WWW document]. URL http://www.who.int/nmh/global _monitoring_framework/ (accessed May 2013).

24. Friel S, Labonte R, Sanders D. Measuring progress on dietrelated NCDs: the need to address the causes of the causes. Lancet 2013; 381: 903-904.

25. World Health Organization. Global Strategy on Diet, Physical Activity and Health: A Framework to Monitor and Evaluate Implementation. World Health Organization: Geneva, 2006.

26. Institute of Medicine. Progress in Preventing Childhood Obesity: How Do We Measure Up? National Academies Press: Washington, DC, 2007.

27. European Commission. The EU Platform on Diet, Physical Activity and Health: founding statement, 2005. [WWW document]. URL http://ec.europa.eu/health/ph_determinants/life_style/ nutrition/platform/docs/platform_charter.pdf (accessed January 2013).

28. World Health Organization. Set of Recommendations on the Marketing of Foods and Non-alcoholic Beverages to Children. World Health Organization: Geneva, 2010.
29. Swinburn B, Sacks G, Vandevijvere $S$ et al. International Network for Food and Obesity/non-communicable diseases Research, Monitoring and Action Support (INFORMAS): overview and key principles. Obes Rev 2013; 14 (Suppl. 1): 1-12. 30. United Nations. United Nations Global Compact, 2013. [WWW document]. URL http://www.unglobalcompact.org/ (accessed May 2013).

31. Streets J, Levy C, Erskine A, Hudson J. Global Risk: Absolute Risk of Obesity. Geneva \& London: UBSWarburg Global Equity Research. 27 November, 2002.

32. Langlois A, Adam V, Powell A. Food Manufacturing: obesity the big issue. London: JP Morgan European Equity Research. 16 April, 2003.

33. Langlois A, Crossley R. The Proof of the Pudding ... Benchmarking ten of the world's largest food companies' response to obesity and related health concerns, 2008. [WWW document]. URL http://www.insight-investment.co.uk/global/documents/ riliterature/367922/proof_of_the_pudding_pres.pdf (accessed January 2013).

34. Bank of America and Merrill Lynch. Globesity - the Global Fight Against Obesity. 21 June 2012, 2012. [WWW document]. URL http://www.foodpolitics.com/wp-content/uploads/GlobesityReport_12.pdf (accessed November 2012).

35. Macmullan J. Left wanting more: Food company policies on marketing to children, 2010. [WWW document]. URL http:// www.consumersinternational.org/media/540105/left_wanting _more.pdf (accessed January 2013).

36. Kolish E, Hernandez M, Blanchard K. The Children's Food \& Beverage Advertising Initiative in Action. A report on compliance and implementation during 2010 and a five year retrospective: 2006-2011, 2011. [WWW document]. URL http://www.bbb.org/ us/storage/16/documents/cfbai/cfbai-2010-progress-report.pdf (accessed December 2013).

37. StanMark Project. The StanMark Project - Project summary, 2013. [WWW document]. URL http://www.iaso.org/policy/ marketing-children/stanmarkproject/ (accessed August 2013).

38. International Association for the Study of Obesity (IASO). World policy on marketing to children map, 2012. [WWW document]. URL http://www.iaso.org/policy/marketing-children/policy -map/ (accessed October 2012).

39. Yale Rudd Center for Food Policy and Obesity. Marketing pledges, 2012. [WWW document]. URL http://www .yaleruddcenter.org/marketingpledges (accessed October 2012). 40. Wootan M, Batada A, Balkus O. Food Marketing Report Card: An Analysis of Food and Entertainment Company Policies to Self-Regulate Food and Beverage Marketing to Children, 2010. [WWW document]. URL http://cspinet.org/new/pdf/ marketingreportcard.pdf (accessed January 2013).

41. King L, Hebden L, Grunseit A, Kelly B, Chapman K. Building the case for independent monitoring of food advertising on Australian television. Public Health Nutr 2012; 4: 1-6.

42. Allder J. Takeaway health: how takeaway restaurants can affect your chances of a healthy diet. London: National Consumer Council, 2008.

43. Macmullan J. Fried and Tested: An Examination of the Marketing of Fast Food to Children. Consumers International: London, 2009.

44. Harris J, Schwartz M, Brownell K et al. Fast Food FACTS: Evaluating Fast Food Nutrition and Marketing to Youth, 2010. [WWW document]. URL http://www.rwjf.org/files/research/ 20101108fffactsreport.pdf (accessed January 2013).

45. Dunford E, Webster J, Barzi F, Neal B. Nutrient content of products served by leading Australian fast food chains. Appetite 2010; 55: 484-489. 
46. Bauer KW, Hearst MO, Earnest AA, French SA, Oakes JM, Harnack LJ. Energy content of U.S. Fast-food restaurant offerings: 14-year trends. Am J Prev Med 2012; 43: 490497.

47. Dibb S. Healthy Competition: How Supermarkets can Affect your Chances of A Healthy Diet. London: National Consumer Council; 2005.

48. Dibb S. Rating Retailers for Health: How Supermarkets can Affect your Chances of a Healthy Diet. National Consumer Council: London, 2004.

49. Haigh C, Durham S. Checkouts checked out. How supermarkets and high street stores promote junk food to children and their parents. Children's Food Campaign. Sustain. March 2012, 2012. [WWW document]. URL http://www.sustainweb.org/resources/ files/reports/Checkouts_checked_out.pdf (accessed November 2012).

50. Koplan J, Brownell K. Response of the food and beverage industry to the obesity threat. J Am Med Assoc 2010; 304: 14871488.

51. Kraak VI, Harrigan PB, Lawrence M, Harrison PJ, Jackson MA, Swinburn B. Balancing the benefits and risks of publicprivate partnerships to address the global double burden of malnutrition. Public Health Nutr 2012; 15: 503-517.

52. UK Department of Health. The Public Health Responsibility Deal, 2011. [WWW document]. URL http://www.dh.gov.uk/ prod_consum_dh/groups/dh_digitalassets/documents/digitalasset/ dh_125237.pdf (accessed July 2013).

53. Kraak V, Story M. A public health perspective on healthy lifestyles and public-private partnerships for global childhood obesity prevention. J Am Diet Assoc 2010; 110: 192-200.

54. UK House of Lords, Science and Technology Select Committee. 2nd Report of Session 2010-12. Behaviour Change, 2011. [WWW document]. URL http://www.publications.parliament.uk/ pa/ld201012/ldselect/ldsctech/179/179.pdf (accessed July 2013).

55. Access to Nutrition Index. Access to Nutrition Index, 2013. [WWW document]. URL http://www.accesstonutrition.org (accessed March 2013).

56. Story M, Kaphingst KM, Robinson-O'Brien R, Glanz K. Creating healthy food and eating environments: policy and environmental approaches. Annu Rev Public Health 2008; 29: 253272.

57. Cairns G, Angus K, Hastings G. The Extent, Nature and Effects of Food Promotion to Children: A Review of the Evidence to December 2008. World Health Organization: Geneva, 2009.

58. Neal B, Sacks G, Swinburn B et al. Monitoring the levels of important nutrients in the food supply. Obes Rev 2013; 14 (Suppl. 1): 49-58.

59. Kelly B, King L, Baur L et al. Monitoring food and nonalcoholic beverage promotions to children. Obes Rev 2013; 14 (Suppl. 1): 59-69.
60. Rayner M, Wood AT, Lawrence M et al. Monitoring the health-related labelling of foods and non-alcoholic beverages in retail settings. Obes Rev 2013; 14 (Suppl. 1): 70-81.

61. Lee A, Ni Mhurchu C, Sacks G et al. Monitoring the price and affordability of foods and diets globally. Obes Rev 2013; 14 (Suppl. 1): 82-95.

62. Hastings G. Why corporate power is a public health priority. BMJ 2012; 345: e5124.

63. Union of Concerned Scientists. Heads They Win,Tails We Lose. How Corporations Corrupt Science at the Public's Expense, 2012. [WWW document]. URL http://www.ucsusa.org/assets/ documents/scientific_integrity/how-corporations-corrupt-science .pdf (accessed November 2012).

64. Bowens R. Understanding the ISO 26000 Social Responsibility Standard and how it relates to and can be assessed alongside other standards, 2011. [WWW document]. URL http://www .sgs.com/white-paper-library/iso-26000-information-request.htm (accessed September 2012).

65. International Organization for Standardization. ISO $26000-$ Social responsibility. Project overview, 2011. [WWW document]. URL http://www.iso.org/iso/iso_catalogue/management _and_leadership_standards/social_responsibility/sr_iso26000 _overview.htm (accessed September 2012).

66. Global Reporting Initiative (GRI). Global Reporting Framework, 2011. [WWW document]. URL http://www .globalreporting.org/ReportingFramework/ (accessed September 2012).

67. Corporate Europe Observatory. A red light for consumer information: the food industry's $€ 1$-billion campaign to block health warnings on food, 2010. [WWW document]. URL http:// www.corporateeurope.org/lobbycracy/content/2010/06/red-light -consumer-information (accessed September 2012).

68. Simon M. Best public relations that money can buy: a guide to food industry front groups. Center for Food Safety, 2013. [WWW document]. URL http://www.centerforfoodsafety.org/files/front groups final 84531.pdf (accessed May 2013).

69. Hartocollis A. Failure of state soda tax plan reflects power of an antitax message. The New York Times, 2 July 2010 [serial online], 2010. [WWW document]. URL http://www.nytimes.com/ 2010/07/03/nyregion/03sodatax.html?emc=eta1\&pagewanted =print (accessed April 2013).

70. Spolar C, Eaton J. As soda tax bubbles up, food lobby mobilizes industry groups spent more than $\$ 24$ million this year to sway lawmakers. Huffington Post [serial online], 2009. [WWW document]. URL http://huffpostfund.org/stories/2009/11/soda -tax-bubbles-food-lobby-mobilizes (accessed November 2012).

71. Swinburn B, Vandevijuere S, Kraak VI et al. The government healthy food environment policy index for monitoring and benchmarking government policies and actions to improve the healthiness of food environments. Obes Rev 2013; 14 (Suppl. 1): $24-37$. 